\title{
ANALISIS ALTERNATIF PEMILIHAN BIAYA SIKLUS HIDUP PADA MASA PEMELIHARAAN RUAS JALAN JANTI - PRAMBANAN KM 7+759-8+750
}

\author{
Rayendra $^{1}$ \\ ${ }^{1}$ Staf Pengajar Program Studi Teknik Sipil, Fakultas Teknik Sipil dan Perencanaan \\ Universitas Islam Indonesia \\ Email: rayendra@uii.ac.id
}

\begin{abstract}
The highway is one of the land transportation infrastructure that serves to connect one area to another for public activities such as economics and social activities. Safe, comfortable, and efficient roads are not avoided by the availability of a flat road and no significant road damage. This research to calculate the life cycle cost analysis of the road with the calculation of pavement thickness that has been done by Ramadhani (2017). The method used in this research is by study case method, by collecting data about Janti-Prambanan Road section KM $7+750-8$ +750 and analyzing life cycle cost by estimating road maintenance that will be done during the life of the plan.Based on the analysis that has been done, the cost of construction or initial cost that must be issued based on the thickness of pavement set by Ramadhani (2017) with the total thickness of paved layer $50 \mathrm{~cm}$ is Rp. 14,089,007,000. The cost of maintenance at Alternative1 is Rp. 2.565.778.485,91 and at Alternative2 is Rp. 2,555,861,411.86. The total cost of the road life cycle in Alternative 1 is $R p$. 16.654.785.485,91 while at Alternative 2 of $R p$. 16,644,868,411.86. Analysis of the lifecycle cost of the two alternatives found EUAC for Alternative 1 is Rp. 65,649.89, while for Alternative 2 is Rp. 65,610.80. So that can be said by advancing the rehabilitation at least save on maintenance costs.
\end{abstract}

Keywords: LCCA, maintenance strategy, maintenance dan rehabilitation, life cycle cost, budget planning.

\section{PENDAHULUAN}

Jalan raya merupakan salah satu prasarana transportasi darat yang berfungsi untuk menghubungkan satu daerah ke daerah lain untuk kegiatan-kegiatan publik seperti kegiatan ekonomi dan sosial. Seiring dengan semakin bertambahnya jumlah penduduk di Indonesia khususnya di D.I. Yogyakarta maka dibutuhkan kondisi jalan raya yang aman, nyaman dan berdaya guna untuk menjunjang kebutuhan ekonomi masyarakat. Jalan yang aman, nyaman dan berdaya guna tidak luput dari ketersediaan jalan yang rata dan tidak adanya kerusakan jalan yang berarti. Sebagai salah satu infrastruktur dalam bidang transportasi adalah jalan raya, maka rencana proyek pembanguanan jalan diperlukan dari perencanaan hingga pemeliharaan jalan tersebut termasuk penanganan kerusakan-kerusakan yang terjadi selama umur rencana.

Sebuah jalan yang rusak jika tidak segera ditangani akan menyebabkan semakin parahnya kerusakan, hal ini membuat biaya perbaikan yang harus dikeluarkan menjadi lebih besar. Agar ruas jalan tersebut mempunyai kemampuan pelayanan yang aman, nyaman dan berdaya guna, perlu adanya analisis biaya siklus hidup jalan raya. Analisis biaya siklus hidup atau Life Cycle Cost Analysis (LCCA) adalah salah satu metode dalam sistem manajemen jalan, dengan LCCA dapat digunakan untuk pengambilan keputusan dalam pemilihan strategi dengan biaya yang paling efektif dan efisien. Analisis biaya siklus hidup ini menggunakan komponen utama, yaitu: biaya pengelola yang terdiri dari biaya konstruksi, biaya pemeliharaan dan biaya rehabilitasi. 
Evaluasi kerusakan jalan dapat dilakukan dengan beberapa cara, namun yang sering dilakukan di Indonesia adalah dengan metode Bina Marga dan metode Pavement Condition Index (PCI). Evaluasi kerusakan jalan merupakan penilaian kondisi kerusakan permukaan jalan secara visual yang digunakan dalam menentukan bentuk pemeliharaan yang akan dilakukan. Pemeliharaan jalan adalah kegiatan penanganan jalan yang berupa pencegahan, perawatan dan perbaikan yang diperlukan untuk mempertahankan kondisi jalan agar tetap berfungsi secara optimal melayani lalu lintas sehingga umur rencana yang ditetapkan dapat tercapai (Peraturan Mentri PU No.13 tahun 2011). Sehingga rencana proyek akan menjadi rencana yang baik, hal ini telah dijelaskan oleh Sudarsana dan Swastika (2012) dalam Giyatno (2016) bahwa kajian ekonomi kerusakan jalan pada dasarnya berisi tentang acuan dan pedoman dalam penyusunan rencana suatu proyek yang akan dilaksanakan, sehingga menghasilkan suatu rencana yang baik.

Penelitian ini melanjutkan dari penelitian Ramadhani (2017) untuk menghitung analisis biaya siklus hidup jalan dengan perhitungan tebal perkerasan yang telah dilakukan. Dalam pelaksanaan proyek konstruksi terdapat lima tahap, yaitu tahap perencanaan, tahap studi kelayakan, tahap perancangan detail atau detail design, tahap konstruksi dan tahap pemeliharaan. Pada penelitian ini memfokuskan pada tahap konstruksi dan tahap pemeliharaan jalan, karena tahap perancangan sebelumnya telah dilakukan oleh Ramadhani (2017). Lebih lanjut dijabarkan bahwa secara umum ruas jalan Jogja-Solo ini dapat dikatakan sebagian besar jalan dalam kondisi mulus, namun juga ditemui kondisi jalan yang bergelombang dan berlubang di beberapa titik. Salah satu ruas yang terdapat beberapa kerusakan tersebut adalah pada KM. 7+750$8+750$.

Sebuah jalan yang rusak jika tidak segera ditangani akan menyebabkan semakin parahnya kerusakan, hal ini membuat biaya perbaikan yang harus dikeluarkan menjadi lebih besar. Agar ruas jalan tersebut mempunyai kemampuan pelayanan yang aman, nyaman dan berdaya guna, perlu adanya analisis biaya siklus hidup jalan raya.

Analisis biaya siklus hidup atau Life Cycle Cost Analysis (LCCA) adalah salah satu metode dalam sistem manajemen jalan, dengan LCCA dapat digunakan untuk pengambilan keputusan dalam pemilihan strategi dengan biaya yang paling efektif dan efisien. Analisis biaya siklus hidup ini menggunakan komponen utama, yaitu: biaya pengelola yang terdiri dari biaya konstruksi, biaya pemeliharaan dan biaya rehabilitasi.

Penelitian ini bertujuan untuk mengetahui biaya siklus hidup dengan membuat estimasi biaya konstruksi konstruksi dengan SNI dan total biaya masing-masing alternatif pemeliharaan jalan. Dalam pencapai tujuan penelitian, maka lingkup penelitian dibatasi pada pada ruas Jalan Nasional Janti Prambanan KM 7+750 - 8+750 dimana metode perkerasan dilakukan dengan metode Bina Marga 2013 yang sebelumnya telah dilakukan oleh Ramadhani (2017).

Dalam kajian ini, akan diperoleh besarnya nilai anggaran biaya pemeliharaan jalan, sesuai dengan jenis dan tingkat kerusakan jalan serta menghitung nilai kerugian masyarakat sebagai akibat dampak negatif kerusakan jalan pada masyarakat sekitar ruas jalan yang mengalami kerusakan meliputi ketidaknyamanan dalam perjalanan dan kerugian ekonomi. Maka, biaya merupakan salah hal yang harus direncanakan dalam proses evaluasi kerusakan jalan sesuai dengan Peraturan Mentri PU No.13 tahun 2011 di atas.

\section{Perkerasan Jalan}

Perkerasan jalan digunakan untuk melayani/mampu menahan beban lalu lintas yang terdiri dari campuran antara agregat dengan bahan ikat. Menurut Sukirman (1999) berdasarkan bahan pengikatnya, konstruksi perkerasan jalan dapat dibedakan menjadi tiga yaitu, konstruksi perkerasan 
lentur (flexible pavement), konstruksi perkerasan kaku (rigid pavement) dan konstruksi perkerasan komposit (composite pavement).Perkerasan lentur (flexible pavement) adalah perkerasan yang menggunakan aspal sebagai bahan pengikat. Lapisan-lapisan perkerasannya bersifat memikul dan menyebarkan beban lalu lintas ke tanah dasar. Lebih lanjut, dijelaskan bahwa perkerasan lentur terdiri dari beberapa lapisan yaitu: lapis permukaan (surface), lapis pondasi atas (base), lapis pondasi bawah (subbase) dan lapisan tanah dasar (subgrade) seperti yang dapat diilustrasikan pada Gambar 1 berikut.

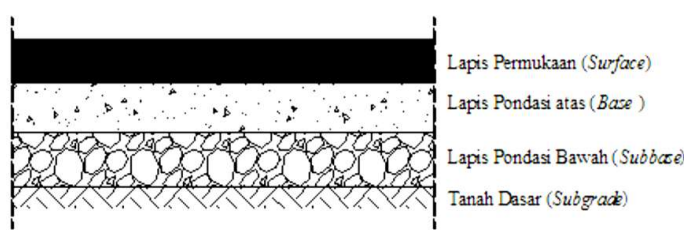

Gambar 1 Susunan Konstruksi Perkerasan Lentur (Sumber: Sukirman, 1999)

\section{Desain Tebal Perkerasan}

Dalam kebijakan desain, menurut Bina Marga 2017, desain yang baik harus memiliki kriteria-kriteria sebagai berikut:

1. menjamin tercapainya tingkat layanan jalan sesuai umur rencana,

2. merupakan discounted-life-cycle cost yang terendah,

3. mempertimbangkan kemudahan pelaksanaan dan pemeliharaan,

4. menggunakan material secara efisien dan memanfaatkan material lokal semaksimal mungkin,

5. mempertimbangkan faktor keselamatan jalan, dan

6. mempertimbangkan kelestarian lingkungan.

Metode yang dapat digunakan untuk mendesain atau merancang perkerasan sebuah jalan selain dikeluarkan oleh Bina Marga dari Indonesia, beberapa metode lain yang dapat digunakan diantaranya AASHTO, The Asphalt Institute dari
Amerika, dan Road Note dari Inggris serta NAASRA dari Australia.

\section{Analisis Biaya Siklus Hidup Perkerasan Jalan}

Analisis biaya siklus hidup (life cycle cost analysis) merupakan teknik analisis yang dibangun berdasarkan pada prinsip-prinsip ekonomi untuk mengevaluasi ekonomi jangka panjang yang efisien, yang digunakan sebagai bahan pertimbangan dalam melakukan investasi. Menggabungkan investasi awal dan investasi masa yang akan datang (agency cost), biaya yang dikeluarkan oleh konsumen (user cost) dan biaya lainnya selama umur investasi (Federal Highway Administation, 1998).

Metode LCCA merupakan salah satu metode dalam sistem manajemen jalan. Dengan metode LCCA, dapat dilakukan pengambilan keputusan dalam pemilihan strategi pemilihan jalan dengan biaya yang paling efektif dan efisien. Menurut Federal Highway Administration (1998), LCCA adalah teknik analisis yang menggunakan prinsip-prinsip ekonomi dalam rangka untuk mengevaluasi jangka panjang alternatif investasi pilihan. Analisis ini memungkinkan perbandingan total biaya desain bersaing alternatif dengan manfaat yang setara.

\section{Pemeliharaan Jalan}

Menurut Peratuan Menteri Pekerjaan Umum No. 13 tahun 2011 mengenai Tata Cara Pemeliharaan dan Penilikan Jalan, pemeliharaan jalan adalah kegiatan penanganan jalan yang berupa pencegahan, pemeliharaan dan perbaikan yang diperlukan untuk mempertahankan kondisi jalan agar tetap berfungsi secara optimal melayani lalu lintas sehingga umur rencana yang ditetapkan dapat tercapai. Pemeliharaan jalan meliputi pemeliharaan rutin jalan, pemeliharaan berkala jalan, rehabilitasi jalan dan rekonstruksi jalan.

Pemilihan penanganan pemeliharaan jalan menurut Peratuan Mentri Pekerjaan Umum No. 13 tahun 2011 dapat dilakukan 
berdasarkan persentase kerusakan terhadap luas lapis perkerasaan permukaa seperti yang ditunjukkan pada Tabel 1 berikut ini.

Tabel 1 Penentuan Program Penanganan Pemeliharaan Jalan Berpenutup Aspal/

Beton Semen (Permen PU No. 13 Tahun 2011)

\begin{tabular}{|c|c|c|}
\hline Kondisi Jalan & $\begin{array}{c}\text { Persentase } \\
\text { Batasan } \\
\text { Kerusakan }\end{array}$ & $\begin{array}{c}\text { Program } \\
\text { Penanganan }\end{array}$ \\
\hline Baik (B) & $<6 \%$ & $\begin{array}{c}\text { Pemeliharaan } \\
\text { rutin }\end{array}$ \\
\hline Sedang (S) & $6-<11 \%$ & $\begin{array}{c}\text { Pemeliharaan } \\
\text { rutin/ berkala }\end{array}$ \\
\hline $\begin{array}{c}\text { Rusak Ringan } \\
\text { (RR) }\end{array}$ & $11-<$ & $\begin{array}{c}\text { Pemeliharaan } \\
\text { rehabilitasi }\end{array}$ \\
\hline $\begin{array}{c}\text { Rusak Berat } \\
\text { (RB) }\end{array}$ & $>15 \%$ & $\begin{array}{c}\text { Rekonstruksi/ } \\
\text { peningkatan } \\
\text { struktur }\end{array}$ \\
\hline
\end{tabular}

\section{Biaya Siklus Hidup}

Menurut FHWA (1998), biaya siklus hidup atau life cycle cost (LCC) mencakup dua jenis biaya, yaitu biaya agensi (agency cost) dan biaya pengguna (user cost). Shanin (1994) menjelaskan bahwa LCC harus dianalisis guna penentuan solusi dengan biaya yang paling efektif.

Beberapa jenis biaya yang digunakan dalam melakukan analisis LCC untuk menentukan alternatif pemeliharaan dan rehabilitasi terlihat pada Gambar 2 berikut.

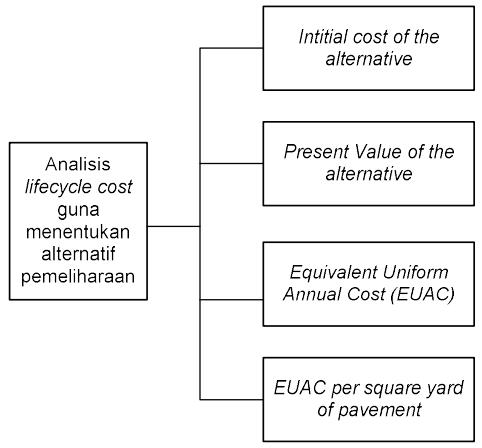

Gambar 2. Analisis LCC untuk Menentukan

Alternatif Pemeliharaan Jalan i(sumber: FHWA, 1998)
1. Initial cost of the alternative (first year cost), initial cost adalah nilai sekarang dari biaya alternatif dan mengabaikan segala biaya mendatang. Initial costakan disimbolkan dengan $\mathrm{C}_{1}$.

2. Present value of the alternative (discounted cost of the alternative in present dollars, using interest and inflation rates), dalam analisis ekonomi, pengaruh bunga dan tingkat inflasi biasanya diperhitungkan. Tingkat inflasi digunakan untuk menyesuaikan biaya masa depan pada alternatif pemeliharaan dan perbaikan, dengan rumus berikut:

$\mathrm{C}_{\mathrm{mt}}=\mathrm{C}_{\mathrm{m}}(1+\mathrm{r})^{\mathrm{t}}$

Dengan;

$\mathrm{C}_{\mathrm{mt}}=$ biaya pemeliharaan dan perbaikan dimasa mendatang

$\mathrm{C}_{\mathrm{m}}$ = biaya pemeliharaan dan perbaikan dimasa sekarang

$\mathrm{r}$ = tingkat inflasi tahunan dalam decimal

$\mathrm{t}=$ waktu ditahun mendatang.

Rumus tersebut menjadikan semua harga dianggap pada harga dasar yang setara. Dengan menerapkan tingkat suku bunga (i), dapat mengubah biaya masa depan menjadi biaya sekarang. Nilai sekarang dari biaya masa depan dapat dihitung dengan rumus berikut:

$\mathrm{PV}=\frac{C_{m t}}{(1+i)^{t}}$ atau $\mathrm{PV}=\mathrm{C}_{\mathrm{m}} \frac{(1+r)^{t}}{(1+i)^{t}}$

Dengan:

$\mathrm{PV}=$ nilai sekarang

$\mathrm{C}_{\mathrm{mt}}=$ biaya pemeliharaandan perbaikan dimasa mendatang

$\mathrm{C}_{\mathrm{m}}=$ biaya pemeliharaan dan perbaikan dimasa sekarang

$\mathrm{r}=$ tingkat inflasi tahunan dalam decimal

$\mathrm{i}=$ tingkat suku bunga dalam decimal

$\mathrm{t}=$ waktu ditahun mendatang

Serangkaian kegiatan pemeliharaan dan perbaikan ditambahkan dengan biaya awal, $\mathrm{C}_{1}$, dalam nilai sekarang dari semua biaya masa depan yang telah disesuaikan dengan tingkat inflasi dan suku bunga 
merupakan nilai sekarang yang dapat digunakan sebagai alat dalam proses pengambilan keputusan. Nilai sekarang dari rangkaian biaya tersebut adalah sebagai berikut:

$\mathrm{PV}=\mathrm{C}_{1}+\sum_{t=1}^{N} \frac{C_{m t}}{(1+i)^{t}}$

atau,

$\mathrm{PV}=\mathrm{C}_{1}+\sum_{t=1}^{N} C_{m t} \frac{(1+r)^{t}}{(1+i)^{t}}$

dengan;

$\mathrm{PV}=$ nilai sekarang

$\mathrm{C}_{\mathrm{mt}}=$ biaya pemeliharaandan perbaikan dimasa mendatang

$\mathrm{C}_{\mathrm{m}}=$ biaya pemeliharaan dan perbaikan dimasa sekarang

$\mathrm{r}=$ tingkat inflasi tahunan dalam decimal

I = tingkat suku bunga dalam decimal

$\mathrm{T}=$ waktu ditahun mendatang

$\mathrm{N}=$ jumlah tahun dalam periode analisis

3. Equivalent uniform annual cost (EUAC) of the alternative (present value cost converted to an annuity), EUAC diperlukan untuk membandingkan antara alternatif pemeliharaan dan perbaikan yang ada. Untuk menghitung EUAC dapat dilakukan dengan mengalikan nilai sekarang dan Capital Recovery Factor (CRF), atau dapat dirumuskan sebagai berikut:

$$
\begin{aligned}
& \mathrm{EUAC}=\mathrm{CRF} \times \mathrm{PV} \\
& \mathrm{CRF}=\frac{i(1+i)^{N}}{(1+i)^{N}-1}
\end{aligned}
$$

dengan;

$$
\text { EUAC = equivalent uniform annual }
$$

$$
\begin{aligned}
& \mathrm{CRF}=\text { capital recovery factor } \\
& \mathrm{PV}=\text { nilai sekarang } \\
& \text { I = tingkat suku bunga dalam } \\
& \text { decimal } \\
& \mathrm{T}=\text { waktu ditahun mendatang } \\
& \mathrm{N} \quad=\text { jumlah tahun dalam periode }
\end{aligned}
$$

4. EUAC per square yard of pavement, EUAC dibagi dengan luas permukaan perkerasan untuk mendapatkan EUAC per square yard of pavement.

Perhitungan biaya dapat dihitung dengan spesifikasi umum pekerjaan konstruksi jalan, spesifikasi umum ini tecantum dalam Pedoman Analisis Harga Satuan Pekerjaan (AHSP) Bidang Bina Marga. Spesifikasi umum pekerjaan konstruksi jalan dan jembatan yang diterbitkan oleh Direktorat Jendral Bina Marga tahun 2014 atau Spesifikasi Umum 2010 Revisi 3 yang berlaku di Ditjen Bina Marga terdiri atas 10 Divisi.

\section{Rencana Anggaran Biaya}

Menurut Ibrahim (1993), yang dimaksud rencana anggaran biaya (begrooting) suatu bangunan atau proyek adalah perhitungan banyaknya biaya yang diperlukan untuk bahan dan upah, serta biaya-biaya lain yang berhubungan dengan pelaksanaan bangunan atau proyek tersebut. Analisis biaya yang dilakukan bersumber dari Pedoman Analisa Bidang Satuan Pekerjaan Bina Marga tahun 2016, dimana struktur analisis dapat dilihat pada Gambar 3 berikut.

Biaya dapat dihitung dari penjumlahan masing-masing hasil perkiraan volume dengan harga satuan pekerjaan (HSP), secara umum dapat dirumuskan sebagai berikut:

$\mathrm{RAB}=\sum \mathrm{Vol} \times \mathrm{HSP}$ 


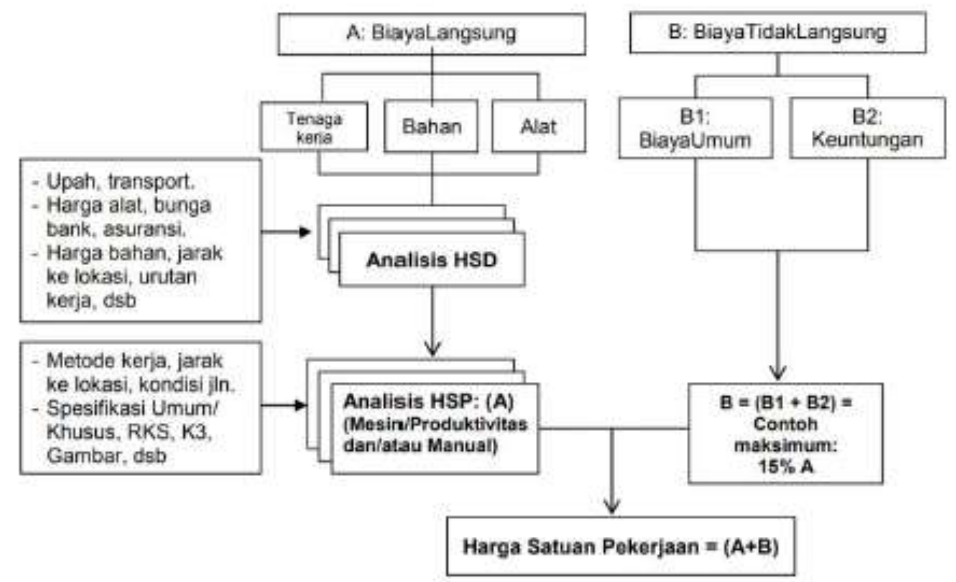

Gambar 3 Struktur Analisis Harga Satuan Pekerjaan (HSP)

(Sumber: Pedoman Analisa Harga Satuan Pekerjaan Bidang Bina Marga, 2016)

Harga satuan pekerjaan atau disebut juga dengan HSP terdiri dari biaya langsung dan biaya tidak langsung. Komponen biaya langsung terdiri atas upah, bahan dan alat, sedangkan komponen biaya tidak langsung terdiri atas biaya umum atau overhead dan keuntungan biaya. Biaya overhead dan keuntungan belum termasuk pajak-pajak yang harus dibayar, besarnya sesuai dengan ketentuan yang berlaku.

Harga Satuan Dasar (HSD) merupakan analisis dari harga satuan untuk tenaga kerja, bahan dan alat yang merupakan komponen utama harga satuan. Harga Satuan Pekerjaan (HSP) setiap mata pembayaran merupakan output dari analisis yang dilakukan, output ini diperoleh dengan suatu proses perhitungan dan masukan-masukan. Masukan yang dimaksud berupa asumsiasumsi, urutan pekerjaan dan penggunaan upah, bahan dan alat. HSD upah, bahan dan alat akan menentukan HSP. Dengan masukan tersebut diperoleh koefisien upah tenaga kerja, koefisien bahan dan koefisien alat.

\section{Metode Penelitian}

Penelitian ini melanjutkan dari penelitian Ramadhani (2017) untuk menghitung analisis biaya siklus hidup jalan dengan perhitungan tebal perkerasan yang telah dilakukan. Data utama yang diperlukan adalah data sekunder dari penelitian sebelumnya terkait desain tebal perkerasan dan data harga satuan dasar material, upah dan alat dengan survei pada lembaga yang berwenang. Analisis data dilakukan dengan beberapa tahapan sebagai berikut.

1. Menentukan rencana pemeliharaan/ strategi pemeliharaan selama umur rencana,

2. AHSP tiap pekerjaan dan volume masing-masing pekerjaan baik biaya konstruksi (initial cost) maupun biaya pemeliharaan (maintenance cost),

3. Menghitung biaya initial costdan maintenance cost selama umur rencana, dan

4. Menghitung total biaya siklus hidup (life cycle cost).

Hal selanjutnya dilakukan pembahasan dan analisis setelah diperoleh data dan informasi dari perhitungan biaya siklus hidup jalan tersebut. Sehingga diperoleh simulasi rencana pemeliharaan jalan dengan alternatif-alternatif solusi yang dilakukan dan mengintepretasi terhadap hasil analisis dengang menarik kesimpulan alternatifyang efektif untuk dilakukan.

\section{Data dan Analisis}

Data pertama yang diperoleh dari penelitian sebelumnya yakni desain tebal perkerasan yang telah dilakukan oleh Ramadhani (2017) 
dan dihitung biaya siklus hidup jalan tersebut. Dimensi desain tebal perkerasan dapat dilihat pada Tabel 2 berikut.

Tabel 2 Dimensi Desain Tebal Perkerasan

\begin{tabular}{|c|l|c|}
\hline No. & \multicolumn{1}{|c|}{ Keterangan } & $\begin{array}{c}\text { Bina Marga } \\
2013\end{array}$ \\
\hline 1 & $A C-W C$ & $4 \mathrm{~cm}$ \\
\hline 2 & $A C-B C$ & $16 \mathrm{~cm}$ \\
\hline 3 & $C T B$ & $15 \mathrm{~cm}$ \\
\hline 4 & LPA kelas A & $15 \mathrm{~cm}$ \\
\hline
\end{tabular}

Pada penelitian ini, strategi pemeliharaanjalan selama 25 tahun pada konstruksi perkerasan lentur (flexible pavement) dengan dua alternatif pemeliharaan jalan yang akan dilakukan selama umur rencana. Penelitian ini memberikan dua alternatif pemeliharaan dengan perbedaan pada waktu rehabilitasi diberikan pada luas permukaan sebesar $18.000 \mathrm{~m}^{2}$, diperoleh dari dimensi persiapan badan jalan (1000m x $8 \mathrm{~m})$.

Pada Alternatif 1 rehabilitasi diberikan pada tahun ke 20 sesuai dengan umur rencana, sedangkan pada Alternatif 2 rehabilitasi pada tahun ke 15, hal ini karena beban kendaraan yang melintas melebihi dari beban rencana serta meningkatnya kondisi ekonomi sehingga jumlah kendaraan semakin meningkat. Hal ini menyebabkan ruas jalan terjadi kerusakan karena tidak mampu memikul beban yang terjadi selama umur rencana. Alternatif pemeliharaan dapat dilipat pada Gambar 3 dan 4 berikut.

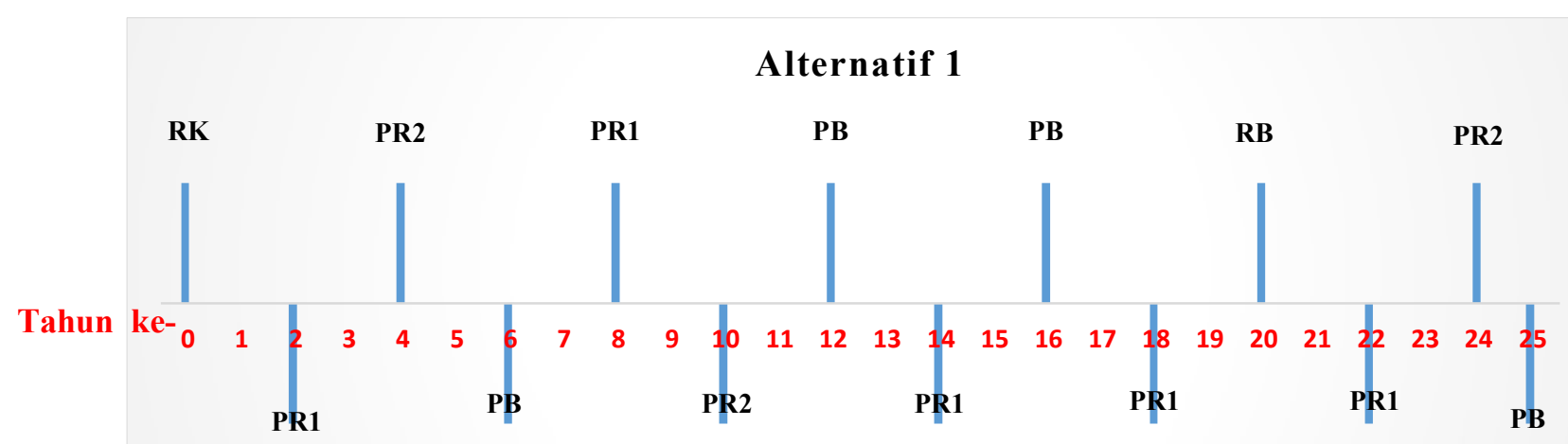

Gambar 4 Rencana Pemeliharaan Jalan Alternatif 1

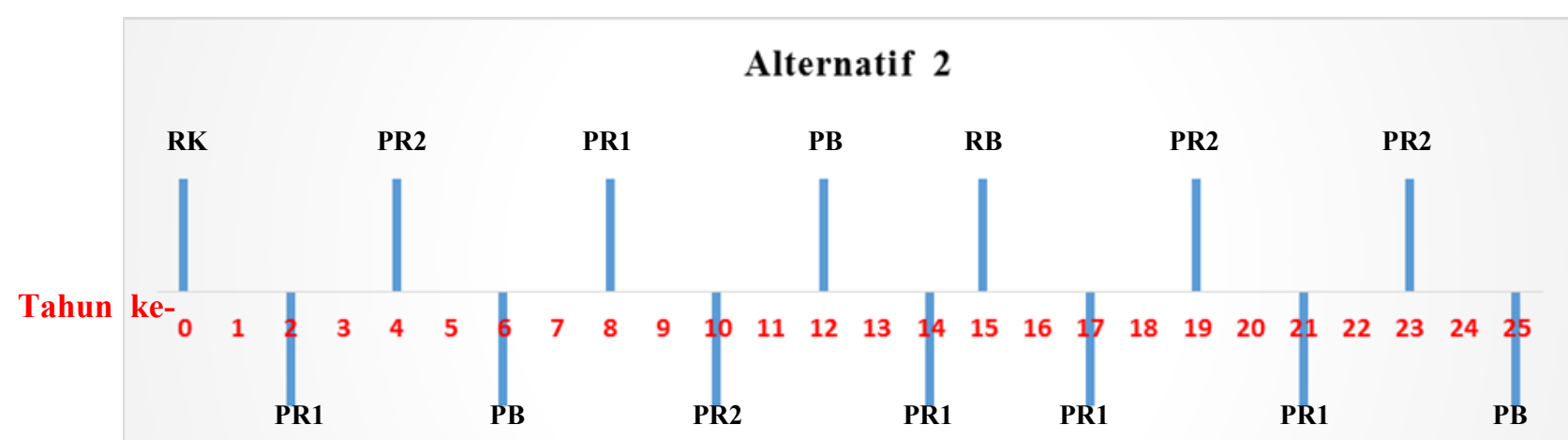

Gambar 5 Rencana Pemeliharaan Jalan Alternatif 2 
Keterangan gambar;

$$
\begin{array}{ll}
\text { RK } & =\text { Rekonstruksi } \\
\text { PR1 } & =\text { Pemeliharaan Rutin 1 } \\
\text { PR2 } & =\text { Pemeliharaan Rutin 2 } \\
\text { PB } & =\text { Pemeliharaan Berkala } \\
\text { RB } & =\text { Rehabilitasi }
\end{array}
$$

Perhitungan biaya dapat diperoleh dari Persamaan 3.8, dari persamaan tersebut maka dibutuhkan perhitungan volume pekerjaan dan harga satuan pekerjaan. Setelah harga satuan dasar diperoleh, maka analisa harga satuan (AHSP) dapat dihitung karena untuk menentukan harga satuan pekerjaan (HSP) diperlukan harga satuan dasar (HSD) tenaga kerja, HSD alat dan HSD bahan. Sebelumnya menentukan dahulu tiap item pekerjaan yang terbagi dalam 10 divisi pekerjaan yang sesuai dengan Pedoman Analisis Harga Satuan Pekerjaan (AHSP) Bidang Bina Marga. Dalam penelitian ini yang diteliti adalah pada badan jalan, maka hanya empat divisi yang akan dihitung dalam initial cost, yaitu Divisi 3 Pekerjaan Tanah, Divisi 5 Perkerasan Berbutir, Divisi 6 Perkerasan Aspal dan Divisi 8 Pengendalian Kondisi dan Pekerjaan Minor.

Koefisien setiap item komponen diperoleh berdasarkan data sekunder dari Pelaksana Jalan Nasional (PJN) Wilayah D.I Yogyakarta PPK 4 tahun 2018. Biaya konstruksi (initial cost) diperoleh dari total uraian pekerjaan (terlihat pada tabel 3). Sebagai contoh pada uraian pekerjaan tanah, diperoleh dari jumlah pekerjaan galian perkerasan beraspal tanpa cold milling machine sebanyak $2.880 \mathrm{~m}^{3}$ dengan harga satuan Rp. 321.918,00 sebersar Rp. 927.123.840,00 dan galian perkerasan berbutir sebanyak $5.400 \mathrm{~m}^{3}$ dengan harga satuan Rp. 58.877,00 sebesar Rp. 317.935.800,00 serta pekerjaan penyiapan badan jalan sebesar $18.000 \mathrm{~m}^{2}$ dengan harga satuan Rp. 7.836,00 sebesar Rp.
141.048.000,00 sehingga total harga pekerjaan diperoleh sebesar Rp. 1.386.107.640,00. Untuk Rekapitulasi Jumlah Harga Pekerjaan Initial Cost dapat dilihat pada Tabel 3.

Pemeliharaan yang akan dilakukan dibagi menjadi empat jenis, yaitu pemeliharaan rutin1, pemeliharaan rutin2, pemeliharaan berkala dan rehabilitasi. Diasumsikan pada pemeliharaan rutin1 dilakukan dengan penutupan lubang $2 \%$ dari luas permukaan perkerasan, pemeliharaan rutin2 dilakukan dengan penutupan lubang $3 \%$ dari luas permukaan perkerasan, pemeliharaan berkala dilakukan dengan pelapisan ulang (overlay) setebal $5 \mathrm{~cm}$ pada $10 \%$ luas permukaan perkerasan, sedangkan rehabilitasi dilakukan dengan pelapisan ulang setebal $8 \mathrm{~cm}$ pada seluruh permukaan perkerasan. Rekapitulasi biaya pemeliharaan untuk pemeliharaan rutin1, pemeliharaan rutin2, pemeliharaan berkala dan rehabilitasi dapat dilihat pada Tabel 4.

Tabel 4 Rekapitulasi Jumlah Harga Pekerjaan Pemeliharaan

\begin{tabular}{|c|l|r|}
\hline No. & Pemeliharaan & $\begin{array}{c}\text { Harga Pekerjaan } \\
\text { (Rp.) }\end{array}$ \\
\hline 1 & $\begin{array}{l}\text { Pemeliharaan } \\
\text { Rutin1 }\end{array}$ & $35.024 .000,00$ \\
\hline 2 & $\begin{array}{l}\text { Pemeliharaan } \\
\text { Rutin2 }\end{array}$ & $52.536 .000,00$ \\
\hline 3 & $\begin{array}{l}\text { Pemeliharaan } \\
\text { Berkala }\end{array}$ & $342.426 .000,00$ \\
\hline 4 & Rehabilitasi & $674.874 .000,00$ \\
\hline
\end{tabular}

Pada Tabel 4 diperoleh initial cost sebesar Rp. 14.089.007.000 termasuk PPN 10\% dengan biaya terbesar yaitu pada pekerjaan perkerasan aspal sebesar Rp. 7.624.294.574,40 dan persentase pekerjaan sebesar $54,11 \%$. Sedangkan biaya pekerjaan paling kecil pada pekerjaan pengembalian kondisi dan pekerjaan minor sebesar Rp. 161.293 .440 dan persentase pekerjaan sebesar $1,15 \%$. 
Tabel 3 Rekapitulasi Jumlah Harga Pekerjaan Initial Cost

\begin{tabular}{|c|c|c|c|c|c|}
\hline No & Uraian & Volume & $\begin{array}{c}\text { Harga } \\
\text { Satuan (Rp.) }\end{array}$ & $\begin{array}{c}\text { Jumlah Harga } \\
\text { Pekerjaan (Rp.) }\end{array}$ & $\begin{array}{c}\text { Total Harga } \\
\text { Pekerjaan (Rp.) }\end{array}$ \\
\hline 1 & Umum & - & - & & - \\
\hline 2 & Drainase & - & - & & - \\
\hline 3 & $\begin{array}{l}\text { Pekerjaan Tanah } \\
\text { - Galian perkerasan tanpa cold milling } \\
\text { machine } \\
\text { - Galian perkerasan berbutir } \\
\text { - Penyiapan Bahan Jalan }\end{array}$ & $\begin{array}{r}2.880 \mathrm{~m}^{3} \\
5.400 \mathrm{~m}^{3} \\
18.000 \mathrm{~m}^{2}\end{array}$ & $\begin{array}{r}321.918 \\
58.877,00 \\
7.836,00\end{array}$ & $\begin{array}{l}927.123 .840,00 \\
317.935 .800,00 \\
141.048 .000,00\end{array}$ & 1.386.107.640,00 \\
\hline 4 & Pelebaran Perkerasan dan Bahu Jalan & - & - & - & - \\
\hline 5 & $\begin{array}{l}\text { Pekerasan Berbutir } \\
\text { - Lapis Pondasi Agregat Kelas A } \\
\text { - Lapis Pondasi Astas Bersemen (Cement } \\
\text { Treated Base) }\end{array}$ & $\begin{array}{l}2.700 \mathrm{~m}^{3} \\
2.700 \mathrm{~m}^{3}\end{array}$ & $\begin{array}{l}428.698,00 \\
918.151,29\end{array}$ & $\begin{array}{l}1.157 .484 .600,00 \\
2.479 .008 .483,00\end{array}$ & 3.636.493.083,00 \\
\hline 6 & $\begin{array}{l}\text { Perkerasan Aspal } \\
\text { - Lapis Resap Perekat } \\
\text { - Lapis Perekat } \\
\text { - Laston Lapir Aus (AC-WC) } \\
\text { - } \text { Laston Lapis Antara (AC-BC) }\end{array}$ & $\begin{array}{r}\text { 7.200 Liter } \\
\text { 2.700 Liter } \\
\text { 1.670,40 Ton } \\
6.681,60 \text { Ton }\end{array}$ & $\begin{array}{r}12.107,00 \\
11.078,00 \\
958.805,00 \\
883.864,00\end{array}$ & $\begin{array}{r}87.170 .400,00 \\
29.910 .600,00 \\
1.601 .587 .872,00 \\
5.905 .625 .702,40\end{array}$ & 7.624.294.574,40 \\
\hline 7 & Struktur & & & & - \\
\hline 8 & $\begin{array}{l}\text { Pengembalian Kondisi dan Pekerjaan } \\
\text { Minor (Marka Jalan Termoplastik) }\end{array}$ & $960,00 \mathrm{~m}^{2}$ & $168.014,00$ & $161.293 .440,00$ & $161.293 .440,00$ \\
\hline 9 & Pekerjaan Harian & - & - & - & - \\
\hline 10 & Pekerjaan Pemeliharaan Rutin & - & - & - & - \\
\hline \multicolumn{2}{|c|}{ (A) Jumlah Harga Pekerjaan } & & & & 12.808.188.737,40 \\
\hline \multicolumn{2}{|c|}{ (B) Pajak Pertambahan Nilai ( PPN ) $=10 \% \times$ (A) } & & & & $1.280 .818 .873,74$ \\
\hline \multicolumn{2}{|c|}{ (C) Jumlah Total Harga Pekerjaan $=(\mathrm{A})+(\mathrm{B})$} & & & & 14.089.007.611,14 \\
\hline \multicolumn{2}{|c|}{ (D) Pembulatan } & & & & 14.089.007.000,00 \\
\hline \multicolumn{6}{|c|}{ Empat Belas Milyar Delapan Puluh Sembilan Juta Tujuh Ribu Rupiah } \\
\hline
\end{tabular}

Untuk menghitung biaya siklus hidup jalan tersebut, dilakukan perhitungan dengan rumus yang tercantum dalam landasan teori. Tabel 5 adalah hasil perhitungan untuk masing-masing alternatif. Pada persamaan 7 di atas, nilai Capital Recovery Factor (CRF) diperoleh sebesar 0,071 dengan dengan membandingkan tingkat suku bunga dalam waktu tertentu.Sehingga dengan diperoleh untuk EUAC pada masing-masing alternatif pada Tabel 6. 
Tabel 5 Biaya Masing-masing Alternatif

\begin{tabular}{|c|c|c|c|c|c|c|c|}
\hline \multirow{2}{*}{$\begin{array}{c}\text { Tahun } \\
\text { ke- }\end{array}$} & \multicolumn{3}{|c|}{ Alternatif 1} & \multirow{2}{*}{$\begin{array}{c}\text { Tahun } \\
\text { ke- }\end{array}$} & \multicolumn{3}{|c|}{ Alternatif 2} \\
\hline & $\mathrm{C}_{1}, \mathrm{C}_{\mathrm{m}}$ & $\mathbf{C}_{\mathrm{mt}}$ & PV & & $\mathrm{C}_{1}, \mathrm{C}_{\mathrm{m}}$ & $\mathrm{C}_{\mathrm{mt}}$ & PV \\
\hline 0 & 14.089 .007 .000 & & & 0 & 14.089 .007 .000 & & \\
\hline 1 & & & & 1 & & & \\
\hline 2 & 35.024 .000 & $38.982 .587,60$ & $35.358 .356,10$ & 2 & 35.024 .000 & $38.982 .587,60$ & $35.358 .356,10$ \\
\hline 3 & & & & 3 & & & \\
\hline 4 & 52.536 .000 & $65.082 .891,85$ & $53.543 .856,19$ & 4 & 52.536 .000 & $65.082 .891,85$ & $53.543 .856,19$ \\
\hline 5 & & & & 5 & & & \\
\hline 6 & 342.426 .000 & $472.151 .626,95$ & $352.326 .813,58$ & 6 & 342.426 .000 & $472.151 .626,95$ & $352.326 .813,58$ \\
\hline 7 & & & & 7 & & & \\
\hline 8 & 35.024 .000 & $53.750 .860,50$ & $36.380 .698,13$ & 8 & 35.024 .000 & $53.750 .860,50$ & $36.380 .698,13$ \\
\hline 9 & & & & 9 & & & \\
\hline 10 & 52.536 .000 & $89.739 .077,26$ & $55.092 .008,89$ & 10 & 52.536 .000 & $89.739 .077,26$ & $55.092 .008,89$ \\
\hline 11 & & & & 11 & & & \\
\hline 12 & 342.426 .000 & $651.022 .874,52$ & $362.513 .896,62$ & 12 & 342.426 .000 & $651.022 .874,52$ & $362.513 .896,62$ \\
\hline 13 & & & & 13 & & & \\
\hline 14 & 35.024 .000 & $74.113 .987,36$ & $37.432 .599,88$ & 14 & 35.024 .000 & $74.113 .987,36$ & $37.432 .599,88$ \\
\hline 15 & & & & 15 & $674.874 .000,00$ & $1.506 .640 .340,22$ & $724.719 .764,32$ \\
\hline 16 & 342.426 .000 & $806.503 .185,07$ & $369.468 .401,61$ & 16 & & & \\
\hline 17 & & & & 17 & $35.024 .000,00$ & $87.027 .710,42$ & $37.969 .901,79$ \\
\hline 18 & 35.024 .000 & $91.814 .234,50$ & $38.150 .710,84$ & 18 & & & \\
\hline 19 & & & & 19 & $52.536 .000,00$ & $145.296 .026,09$ & $57.498 .571,34$ \\
\hline 20 & 674.874 .000 & $1.969 .118 .668,71$ & $742.140 .116,77$ & 20 & & & \\
\hline 21 & & & & 21 & $342.426 .000,00$ & $1.054 .067 .407,93$ & $378.349 .447,89$ \\
\hline 22 & 35.024 .000 & $113.741 .736,97$ & $38.882 .598,12$ & 22 & & & \\
\hline 23 & & & & 23 & $35.024 .000,00$ & $119.997 .532,51$ & $39.067 .753,35$ \\
\hline 24 & 52.536 .000 & $189.896 .095,19$ & $58.880 .685,41$ & 24 & & & \\
\hline 25 & 342.426 .000 & $1.305 .804 .688,37$ & $385.607 .743,77$ & 25 & $342.426 .000,00$ & $1.305 .804 .688,37$ & $385.607 .743,77$ \\
\hline $\mathbf{C}_{1}$ & 2.377.306.000 & Total PV & 2.565.778.485,91 & $\mathbf{C}_{1}$ & 2.377.306.000 & Total PV & 2.555.861.411,86 \\
\hline $\mathrm{C}_{1}+\mathrm{C}_{\mathrm{m}}$ & 16.466.313.000 & Total PV+C1 & 16.654.785.485,91 & $\mathbf{C}_{1}+\mathbf{C}_{m}$ & 16.466.313.000 & Total PV+C1 & 16.644.868.411,86 \\
\hline
\end{tabular}


Tabel 6. Nilai EUAC Masing-masing alternatif Pemeliharaan

\begin{tabular}{|c|c|c|c|c|}
\hline Alternatif & CRF & PV & EUAC & $\begin{array}{c}\text { EUAC per square } \\
\text { yard of pavement }\end{array}$ \\
\hline 1 & 0,071 & Rp. 83.900.554,88 & Rp. 1.181.697.956,02 & Rp. 65.649,89 \\
\hline 2 & 0,071 & Rp. 83.850.596,38 & Rp. 1.180.994.315,24 & Rp. 65.610,80 \\
\hline
\end{tabular}

Tabel 7. Persentase Biaya Pemeliharaan

\begin{tabular}{|c|c|c|c|c|c|}
\hline & Biaya & Total Biaya Siklus \\
Hidup & Bornatif & Biaya \\
Awal & Pemeliharaan & $\begin{array}{c}\text { Persentase } \\
\text { Biaya } \\
\text { Pemeliharaan } \\
\text { terhadap } \\
\text { Biaya Awal } \\
\text { Konstruksi }\end{array}$ & $\begin{array}{c}\text { Persentase } \\
\text { Biaya } \\
\text { Pemeliharaan } \\
\text { terhadap Total } \\
\text { Biaya } \\
\text { SiklusHidup }\end{array}$ \\
\hline 1 & $\begin{array}{c}\text { Rp. } \\
14.089 .007 .000\end{array}$ & $\begin{array}{c}\text { Rp. } \\
16.654 .785 .485,91\end{array}$ & $\begin{array}{c}\text { Rp. } \\
2.565 .778 .485,91\end{array}$ & $84,59 \%$ & $15,41 \%$ \\
\hline 2 & $\begin{array}{c}\text { Rp. } \\
14.089 .007 .000\end{array}$ & $\begin{array}{c}\text { Rp. } \\
16.644 .868 .411,86\end{array}$ & $\begin{array}{c}\text { Rp. } \\
2.555 .861 .411,86\end{array}$ & $84,64 \%$ & $15,36 \%$ \\
\hline
\end{tabular}

Pemeliharaan dibagi menjadi empat jenis yaitu pemeliharaan rutin1, pemeliharaan rutin2, pemeliharaan berkala dan rehabilitasi. Pada Tabel 5 biaya untuk pemeliharaan rutin1 sebesar Rp. 35.024.000, pemeliharaan rutin2 sebesar Rp. 52.536.000,

pemeliharaan berkala sebesar Rp. 342.426.000 dan rehabilitasi sebesar Rp. 674.874.000.Persentase biaya siklus hidup untuk masing-masing ditunjukkan pada tabel 7.

Berdasarkan analisis yang telah dilakukan, penentuan strategi pemeliharaan sangat berpengaruh pada biaya siklus hidup jalan tersebut. Dalam penelitian ini, biaya siklus hidup yang lebih ekonomis yakni pada alternatif kedua saat rehabilitasi diberikan pada tahun ke 15 dengan hemat biaya hingga $0,06 \%$ pada masa rehabilitasi. Sehingga jika pihak-pihak yang memiliki kepentingan akan proyek pembangunan jalan raya dapat mengambil keputusan setelah perhitungan dan rencana yang baik dimulai dari perencanaan hingga pemeliharaan pembangunan jalan. Hal yang tidak bisa diabaikan adalah evaluasi dari setiap pelaksanaan pembangunan proyek secara umum, dan proyek pembangunan jalan secara khusus sehingga perencanaan perkerasan dan treatment akan jalan itu sendiri akan sesuai dengan apa yang telah direncanakan semula. Dikarenakan masih banyak jalan di Indonesia secara umum dan di D.I. Yogyakarta secara khusus beban jalan yang ditahan oleh jalan tidak sesuai dengan beban yang telah direncanakan. Hal ini juga dikuatkan dari hasil wawancara yang dilakukan dengan Pelaksana Jalan Nasional (PJN) Wilayah D.I. Yogyakarta PPK 4 mengatakan bahwa jalan yang ada saat ini tidak dilalui oleh kendaraan dengan beban lalu lintas yang sesuai, sehingga rehabilitasi dilakukan sesuai dengan umur rencana jalan yang telah dilakukan.

\section{KESIMPULAN}

Kesimpulan yang diperoleh berdasarkan hasil analisis yang telah dilakukan pada ruas Jalan Janti-Prambanan KM 7+750$8+750$ adalah sebagai berikut.

1. Biaya konstruksi atau initial cost yang harus dikeluarkan berdasarkan tebal 
perkerasan yang telah ditentukan oleh Ramadhani (2017) dengan total tebal lapis perkerasan $50 \mathrm{~cm}$ adalah sebesar Rp. 14.089.007.000.

2. Biaya pemeliharaan pada Alternatif 1 adalah sebesar Rp. 2.565.778.485,91dan biaya pemeliharaan pada Alternatif 2 adalah sebesar Rp. 2.555.861.411,86. Total biaya siklus hidup jalan tersebut pada Alternatif 1 adalah sebesar Rp. 16.654.785.485,91sedangkan pada Alternatif 2 adalah sebesar Rp. 16.644.868.411,86.

3. Berdasarkan analisis biaya siklus hidup dari kedua alternatif adalah EUAC untuk Alternatif 1 adalah Rp. 65.649,89, sedangkan untuk Alternatif 2 adalah Rp. 65.610,80. Biaya siklus hidup terendah terjadi pada Alternatif 2 yaitu saat rehabilitasi diberikan pada tahun ke 15 . Karena berdasarkan hasil wawancara yang dilakukan dengan Pelaksana Jalan Nasional (PJN) Wilayah D.I Yogyakarta PPK 4 mengatakan bahwa jalan yang ada saat ini tidak dilalui oleh kendaraan dengan beban lalu lintas yang sesuai atau adanya overload, sehingga belum mencapai umur rencana jalan tersebut sudah perlu dilakukan rehabilitasi. Sehingga terjadi keselarasan dengan memajukan masa rehabilitasi setidaknya menghemat biaya hingga $0,06 \%$.

\section{DAFTAR PUSTAKA}

Dirjen PU. 2013. Manual Desain Perkerasan Jalan Nomor 02/M/BM/2013.Direktorat Jendral Bina Marga. Kementrian Pekerjaan Umum.

Federal Highway Administration. 1998. Life Cycle Cost Analysis in Pavement Desain (In Search of Better Investment Decisions). Federal Highway Administration: Pavement Division Interim Technical Bulletin, Publication No. FHWA-SA-98-079.

Giyatno. 2016. Analisis Kerusakan Jalan dengan Metode PCI Kajian Ekonomis dan Strategi Penanganannya (Studi Kasus Ruas Jalan Ponorogo - Pacitan KM 231+000 Sampai Dengan Km 246+000, KM 0+000 di Surabaya). Tesis. (Tidak Diterbitkan). Universitas Muhamadiyah Surakarta.

Ibrahim, Bachtiar. 1993. Rencana dan Estimate Real of Cost. Bumi Aksara. Jakarta.

Mentri Pekerjaan Umum. 2011. Peraturan Mentri PU No. 13 tahun 2011.Direktorat Jendral Bina Marga. Kementrian Pekerjaan Umum.

Peraturan Menteri Pekerjaan Umum Dan Perumahan Rakyat Nomor: 28/Prt/M/2016 Tentang Analisis Harga Satuan Pekerjaan Bidang Pekerjaan Umum.

Ramadhani, Riska Intan. 2017. Evaluasi Tebal Perkerasan Lentur dengan Metode Bina Marga 2013 dan Metode Mekanik-Empirik Menggunakan Program KENPAVE Pada Ruas Jalan Jogja-Solo. Tugas Akhir. Universitas Islam Indonesia. Yogyakarta.

Shahin, M. 1994. Pavement Management for Airport, Roads, and Parking Lots. New York: Springer Science and Business Media, LLC.

Sukirman, S. 1999. Perkerasan Lentur Jalan Raya. Nova. Bandung 